\title{
Teaching Argumentation Analysis and Critical Thinking in the Netherlands
}

\section{F. H. VAN EEMEREN AND R. GROOTENDORST Universiteit van Amsterdam}

\section{The art and theory of argumentation}

The importance of argumentation analysis may become clear once it is realized that not a day passes without a confrontation, without argument and counter-response. Argumentation is encountered everywhere: during meetings, in scientific articles, in film reviews, letters, and in everyday conversation.

The theory of argumentation involves the study of argumentation and its soundness. Research results form the basis for the development of sound and reliable argumentation analysis, in which the best approach towards argument or counter-argument is illustrated. While taking into account interest, age and capacity of the student, suitable methods can be developed and instructional devices can be designed for the teaching of argumentation analysis.

\section{Trends in argumentation theory}

Until about 1950, the study of argumentation in the Netherlands was either purely practical or else a continuation of the classical logic and rhetoric traditions. In the former, the sole aim was to search out clues to the improvement of the practice of argumentation. In the latter, argumentation was dealt with only when in the context of explaining logic or the rhetoric of Aristotle cum suis. The philosophers Toulmin and Perelman have each, individually, provided fresh impetus to argumentation research. In 1958, Toulmin's The Uses of Argument and Perelman and OlbrechtTyteca's La Nouvelle Rhetorique were published, and both books have since inspired numerous followers.

Toulmin's main objection is that a logical model is used in the analysis and evaluation of argumentation. He believes that such a model is not suited to any practical example of argumentation. He develops an analysis model which works on the assumption that when a person puts forward an argument, he always defends a claim (Don't worry, you may continue to live here ${ }^{\prime \prime}$ ) by presenting certain information ("The new owner can't throw you out"), which by means of a justification often only implied, is linked to the claim ("A tenancy contract remains upheld in the event of sale $\left.{ }^{\prime \prime}\right)$.

The soundness of argumentation is, in the long run, dependent on the support which renders the justification plausible. ("It is determined by law that the tenancy is not terminated in the event of sale by owner/landlord.") In view of the fact that in one field justification is rendered plausible by totally different types of support than in others, the soundness of the argument is, according to Toulmin, "field-dependent."

Together with Olbrechts-Tyteca, Perelman has attempted to give a description of argumentation techniques used to win the approval of an audience of a certain viewpoint. For this purpose they distinguish between various types of "audiences": the univer- 
sal audience, which, in principle, includes all reasonable people, and specific audiences. They also distinguish between various types of starting points (facts, assumptions, values, etc.) and set out a list of practical argumentation schemes. These schemes vary from "quasi-logical" argumentation schemes ("We need not be afraid, therefore we need not be afraid of our own fear") to argumentation schemes which are "based on the structure of reality", ("Religious fanatics are the best musicians in the world, they are so very dedicated") or they create the structure of reality ("I can assure you that we can trust him; I've played tennis with him for years"').

According to Perelman and Olbrechts-Tyteca, the outlining of the argumentation schemes provides a vital addition to logic, which otherwise would give a one-sided and incomplete picture of the reality of argument.

The research trends initiated by Toulmin and Perelman for a long time determined the nature of argumentation theory. Although these trends are still significant, a number of new research trends have developed in modern argumentation theory.

In the same way that Perelman and Olbrechts-Tyteca use rhetorical tradition as a basis for the development of a "new rhetoric", protagonists of a 'new dialectic', such as Barth and Krabbe, set rules for arguing parties who wish to resolve their dispute by means of a critical dialogue. The methods used here include those by Lorenzen, Lorenz, and other followers of the "Erlanger Schule", as well as ideas of argumentation theorists such as Crawshay-Williams and Naess. The nomenclature of their argumentation theory is derived from Hamblin, in which they interpret "dialectic" as a critical discussion aimed at settling a dispute, and the term "formal" as a strictly regulated discussion.

Alongside new dialectic, recent years have seen the rise of an important trend in informal logic. A number of authors assume, in a variety of ways, that argument is carried out in colloquial language, and this has a clear bearing on their approach. This is the case, for example, in the works of Fogelin, Scriven, Blair, and Johnson, and in various studies on (informal) fallacies.

Setting aside the divergence of trends, it may be stated that in the past ten years, the scope of the research into argumentation theory has increased tremendously. There are a growing number of publications on argumentation appearing in the United States as well as in Europe. And the number of conferences and other activities devoted currently to argumentation, clearly indicate an increasing institutionalisation of the subject of argumentation theory.

\section{Theory of argumentation and pragmatics}

Argumentation is an attempt to convince another person of one's point of view. Such an attempt is no abstract or mechanical process, but a verbal and social activity aimed at conquering the opponent's doubts. So argumentation should be studied as one element of normal communication and interaction between speakers, and not as a somewhat inadequate logical inference scheme.

This means that in argumentation theory, as opposed to logic, it must be assumed that there will be evidence of polysemy or elements which remain implicit. It can even occur that a person deliberately formulates something which deviates from what he really means, being indirect or ironic. This should all be taken into consideration in argumentation theory.

We believe that this is best dealt with by interpreting argumentation theory, as is done in the fields of discourse analysis and speech communication, as part of normative pragmatics. The development of theory which has already taken place in pragmatics, can be of benefit in the study of argumentation. The develop- 
ment of theory regarding argumentation can, in turn, be of use in the further development of pragmatics.

The theoretical choice for pragmatics results in argumentation being approached as a speech act. Like other speech acts, argumentation must fulfil certain conditions in order to succeed at a communicative and interactional level. Argumentation theory here serves the purpose of, among other things, setting out the conditions and illustrating the consequences of any violations.

\section{Argumentation in a dialectical perspective}

Argumentation consists of (verbal or written) statements which are aimed at resolving a dispute between someone presenting an argument and someone disagreeing. A person who argues has a point of view, which he knows or assumes is doubted by others. Argumentation is an attempt to conquer this doubt in order to prevent or resolve a dispute with other language users.

A person's viewpoint can either be positive or negative. In the former, he argues in favour of something, and in the latter, he argues against it. In both instances he attempts to remove (any) doubt regarding the plausibility of his viewpoint. The greater the doubt with which he is confronted (or with which he assumes he is confronted) the more complex his argument becomes. He is then continually engaged in a critical discussion. In principle, argumentation, whether in a highly complex discourse or a very simple one, forms part of a discussion between the protagonist and a (real or assumed) antagonist. The protagonist defends a viewpoint and the antagonist confronts him with his doubt. In order to resolve a dispute between antagonist and protagonist, it is necessary that the discussion has a dialectical character. This means that the aim of both protagonist and antagonist is to resolve the dispute by means of a regulated discussion in which both parties attempt to present their positions as strongly as possible, and in which both parties try to establish the most viable viewpoint.

A dialectical discussion is a critical discussion which differs from a purely rhetorical one. In a rhetorical discussion, the parties each have the sole aim to be proved right. Using all possible methods varying from imploring argumentation or an appeal to the emotions, to a reference to their own integrity, they try to persuade others.

A rhetorical discussion is characterized by a strong element of effect. Those who are to be persuaded are no more than an audience from whom only applause and no opinion is expected.

In practice, discussants often pursue a rhetorical course, and the opponents are often treated as a passive audience. In spite of this, discussants should, in principle, be given the benefit of the doubt assuming that their contribution, in the absence of evidence indicating the contrary, is dialectical. One consequence of this is that every argument should be analysed as a totality of statements, intended to defend a viewpoint by using rational means in order to conquer the doubt of a critical listener regarding the plausibility of the viewpoint.

A dialectical approach to argumentation upholds this principle. Every argument in this approach is regarded as part of a discussion, explicit or implicit, between two people who are both attempting to resolve a dispute (either open or underlying), by carrying out a critical exchange of words. Such a dialectical approach, in which pragmatic principles can be combined with logical principles, is to be preferred in the analysis of argumentation.

\section{Dialectics and didactics}

A dialectical approach to argumentation entails a certain attitude regarding 
discussion. This attitude may be characterized as a critical rationalist attitude.

A critical rationalist attitude entails, for example, that a person is willing to discuss his viewpoints. It also entails a person formulating his viewpoint as clearly as possible, and renouncing the use of 'immunization strategies', such as referring to emotional opinions, innermost convictions, and unassailable personal principles. This discussion attitude also ensures that any form of criticism, either inappropriate or suspect, will not automatically be rejected or be immune to serious response.

A great deal more may be said on the characteristics of a critical rationalist discussion attitude. For example, a large measure of caution should be exercised in preventing classic fallacies and other manoeuvers which could endanger the level of the discussion. In general, it may be stated that the aim of the critical rationalist attitude is to ensure maximum opportunity for holding a dialectic discussion aimed at resolving a dispute.

The choice for a critical discussion is more than just a scientific principle. It is a choice which carries consequences not only for argumentation analysis, but also for didactics. A critical rationalist attitude should become evident in the pedagogical principles which lie at the root of argumentation analysis.

These principles cannot, for example, include striving for a set of instructions to be followed at any cost. Nor can it be suggested that tailor-made solutions are reached. Generally speaking, we must conclude that a person whom someone is trying to teach should never be regarded as a mere sponge whose process of instruction is finalized when all the facts have been absorbed. The assumption in a 'dialectic' didactic is that a person who wants to learn something is by no means totally ignorant, and already possesses certain skills and knowledge. In this connection, it is important that he is a speaker who argues and responds to another person's argument. Moreover, it is assumed that the person in the process of learning is not a passive register, but an active discussion partner who considers the information offered and, where necessary, responds critically.

This means that when instruction is to be given, material should be offered which fits in with existing knowledge and precipitates further reflection. This reflection should result in greater insight. We believe that such insight can come about only if all the complications which are inherent to certain subjects are acknowledged right from the outset and drawn into the process of reflecting. A combination of 'theoretical' reflection and 'practical' exercise should then result in a person becoming thoroughly familiar with the basics of dialectical analysis of argumentation.

\section{Components of argumentation analysis}

In order to be able to present sound instruction in argumentation analysis, theoretical instruments must be developed which are necessary for solving the problems involved. This requires a systematic explanation of the major characteristics of verbal communication and interaction in general, and of argument and discussion in particular. It should be based on an adequate argumentation theory.

Argumentation theory is sufficiently advanced to allow us to establish that sound argumentation analysis should comprise at least three components. Attention should be given to problems with regards to (1) the analysis of argumentative discourse, (2) the identification of fallacies, and (3) the evaluation of argumentation. And special attention should be given to the problems of presenting an argument.

Before an argument or any other aspect of an argumentative discourse can be adequately evaluated, it is necessary to understand the structure of the discourse. An analytical outline of 
the discourse is therefore necessary, and obviously, can come about only following a thorough analysis. Furthermore, it is of tremendous benefit in evaluating a discourse if one is able to recognize fallacies. Proficiency in drawing up an analytical outline as well as recognizing fallacies is also a useful skill for other reasons. These skills are of continuous use in presenting an argument.

The analysis of an argumentative discourse involves establishing which issues are disputed and which are to be resolved. It involves giving an interpretation of the various speech acts performed during the discourse, as well as an analysis of the structure of the argumentation. This should result in an accurate identification of the dispute which forms the main issue of the (explicit or implicit) discussion and a clear indication of the function of the speech acts which are carried out in order to resolve the dispute. The structure of the argumentation within the discourse should also be indicated.

The identifying of fallacies entails establishing points in an argument or discussion where violations of rules occur, that is, the rules which must be taken into account with a view to resolving the dispute. This, of course, can be established only once rules linked to a critical discussion are clear; only then can one judge as to whether or not the rules are being adhered to. The classic fallacies may all be regarded as abuse of dialectical rules for discussion (in spite of the fact that they are not generally described thus by other authors). Therefore the identification of fallacies involves recognizing breaches of a code of conduct for reasonable discussants.

The study of argumentation should also consist of an outline of the relation between specific breaches of the code of conduct and certain classic fallacies. It should be made clear that the fallacy of argumentum ad baculum, to threaten with violence, amounts to the violation of the basic rule that each discussion partner should freely be able to present any viewpoint he wishes. The fallacy of argumentum ad hominem, the launching of a personal attack, amounts to a violation of the rule that a person's viewpoint should be judged on the quality of his reasoning and not on personal qualities. The fallacy of petitio principii, the circular argument, violates the rule that a person should not implicitly take for granted something yet to be proven.

The evaluation of argumentation involves verifying whether the chosen scheme is reliable. First it should be established exactly which scheme has been used in the argumentation, and then it should be indicated if the chosen scheme can contribute towards resolving the dispute. Argumentation schemes which lead to logical or pragmatic inconsistencies are not suitable for this purpose. For example, a dispute cannot be resolved by simultaneously agreeing and disagreeing with something (logical inconsistency), or by presenting a claim to which the protagonist adds the comment that he himself does not believe it (pragmatic inconsistency).

We believe that in the evaluation of argumentation within the study of argumentation analysis, it is of particular importance to turn to basic principles of logic and pragmatics. Logic, for example, can offer greater insight into the validity of reasoning, and pragmatic into the contextual conditions of argumentation.

\section{Recognizing points of disagreement}

In the illustration which follows, the difference of opinion which father and son try to resolve is a good example of the complex disputes which regularly occur in daily life:

F: Don't you think this is a good magazine, son? Shall we take out a subscription?

S: Yes, it's a good magazine, but I'm not interested in subscribing to it.

F: But if you like the magazine, why on earth not? 
S: The magazine's good, Dad, but its readers are so disgusting.

In order to effectively evaluate a discourse like this, one must first establish exactly which moot points the discourse should dispel. One should also define which steps are used towards resolving the dispute, and the exact structure of the argumentation used should also be established. This entails compiling an analysis of the discourse in which the various points of dispute are identified, in which the discourse is interpreted and the argumentation structure is analysed. In this section we would like to give a brief outline of the method of argumentation analysis which best illustrates how this can be done.

In order to allow for an adequate identification of moot points, a distinction should be made between four standard types of dispute: non-mixed single, mixed single, non-mixed mutliple, and mixed multiple. The distinctions indicate the type of viewpoint taken with regard to a proposition and the number of propositions in relation to an adopted viewpoint. A viewpoint can be positive ("It's the case that...") or negative ("It is not so that..."). A negative viewpoint with regard to one proposition is, for example, "I don't think that Shakespeare is our greatest poet" and a (positive) viewpoint with regard to two propositions is, for example, "I think that the Netherlands should immediately withdraw from NATO and should opt for total disarmament."

A non-mixed single dispute forms the basic type of a dispute. One viewpoint is then adopted (positive and negative) and is presented to doubt one proposition.

a. Peter: "I think the Netherlands should withdraw from NATO."

Ann: "I'm not sure whether the Netherlands should withdraw from NATO."

b. Paula: "I don't believe the Netherlands should withdraw from NATO."

Ann: "I'm not sure whether the Netherlands should not withdraw from NATO."
Other types of disputes can always be analysed into a number of disputes of the basic type, and implicit disputes can always be regarded as a combination of non-mixed single disputes.

The resolving of a dispute always requires a critical discussion of which argumentative discourse forms a part. The discussion can be carried out explicitly, but the speaker or writer attempting to resolve a real or assumed dispute may also anticipate scepticism from his listener or reader. Then we speak of an implicit discussion.

In order to show the position of an argumentative discourse within a discussion, various stages should be distinguished which theoretically are followed. These are the confrontation stage, during which a dispute is established; the opening stage, during which the discussion procedure and rules are agreed upon; the argumentation stage, in which the argumentation is presented with the purpose of resolving the dispute, and the closing stage, during which the outcome of the discussion is established. In a dialectical approach to argumentation, it is assumed that, in principle, an argumentative discourse always forms part of an (explicit or implicit) critical discussion and is always included in the argumentation stage. There may often be references to other (implicit) discussion stages as well.

A critical discussion takes place between a person who fulfils the role of protagonoist regarding a particular viewpoint and a person acting as antagonist regarding the same viewpoint. If the protagonist adopts a positive viewpoint towards a proposition, he tries to justify this by means of argumentations. If he adopts a negative viewpoint, he will attempt to refute the proposition. In the first example, we speak of proargumentation, and in the second, of contra-argumentation. In both instances, the dispute arises because the protagonist presents a viewpoint, and the antagonist throws doubt upon it (or is assumed to do so). The dispute is 
resolved in favour of the protagonist if the antagonist, as a result of the discussion, retracts his doubt, and it is resolved in favour of the antagonist if the protagonist retracts his viewpoint.

A number of questions can also be formulated which are of importance when analysing an argumentative discourse. They are concerned with identification of points of dispute. They indicate aspects to be taken into account during analysis, but offer no guarantee for correct answers. The checklist is as follows:

1. With regard to which propositions is a positive or negative viewpoint adopted?

2. Which viewpoints are expected to be subject to doubt and consequently defended by means of argumentation?

3. What types of dispute form the main issue of the discourse, and of which non-mixed single disputes does it consist?

4. Who acts as protagonist towards the defended viewpoint, and who is antagonist?

5. Apart from the argumentation stage, how are the confrontation stage, opening stage, and closing stage represented?

6. From which points of the dispute is it evident that they have been settled in favour of protagonist or antagonist?

\section{The interpretation of an argumentative discourse}

One of the major problems which can arise in interpreting an argumentative discourse is that certain elements remain implicit. The figure in a cartoon argues, for example, why Dagobert Duck should fly to Venus to deliver a letter. Here we see a good example of a concealed argument:

He has no choice; the person who wrote the letter has bought the stamp.
In order to arrive at a reliable interpretation, a distinction should be made between speech acts which contribute towards resolving the dispute from those which do not. Five basic types of speech acts can be distinguished: assertives, by means of which the speaker or writer claims something; directives, by means of which he tries to get the reader or listener to a particular course of action; commissives, by means of which he commits himself to adopt a course of action; expressives, by means of which he expresses his frame of mind; and lastly, declaratives, by means of which he, as it were, creates a situation. An example of an assertive is: "I'm informing you that...", a directive: "I would like you to...", a commissive: "I promise you...", an expressive: "I contratulate you...", and a declarative: "I hereby declare this meeting open."

As well as assertives, which for example are used in presenting viewpoints and argumentations, a critical discussion will theoretically only include directives which serve the purpose of encouraging argumentation or information, and commissives which serve to give evidence of the acceptance or rejection of viewpoints, challenges, or argumentation, and also to commit oneself to certain agreements on discussion rules as well as discussion procedure. There is also a particular type of declaratives: language usage declaratives. These are speech acts, such as to explain and to define, which serve to clarify another speech act or series of speech acts.

It is not always clear in practice which type of speech act we are dealing with, in which case while interpreting, one will need to examine the verbal and nonverbal context, or alternatively the general or specific background knowledge. A special problem often arises with the occurence of implicit assertives which may serve to present a viewpoint or argumentation, or to carry out a language usage delcarative. Speech acts may also arise in an argumentative discourse which may not appear to be 
assertives, but should nevertheless be regarded as part of the argumentation. For instance, "Women make better interviewers than men; look at Oriana Falacci." In such unclear cases, the strategy of maximal argumentative interpretation should be followed. This will ensure that every part of the argumentation is taken into consideration during analysis, and that the speaker or writer is given his due.

Apart from ordinary implicit speech acts, an argumentative discourse may also include indirect speech acts. These are implicit speech acts whereby the speaker or writer means something other than what he literally says. In order to establish what he means, one must consider the general principles of communication. This means that in the carrying out of speech acts, the following standards should as a rule be taken into consideration: (1) comprehensibility, (2) sincerity, (3) non-superfluity, (4) nonfutility, and (5) suitability. Indirect speech acts can be identified in the statements expressed by the speaker or writer, when the literal meaning violates one or more of these standards and which may be invalidated by attributing an indirect meaning to the statements.

Unexpressed premises can be made explicit by taking into account the presence of indirect speech acts within the argumentation. The argumentation in "Nancy is a true Sinatra, so she is musical", would, literally interpreted, conceal an invalid argument. If we assume that a person presenting the argumentation is no fool, we should seek an interpretation which does not immediately render his argument invalid. This can be found if we assume that the unexpressed premise lies in the statement that all Sinatras are musical. So again, a number of questions can be formulated which will be of use in analysing an argumentative discourse:

1. From which speech acts is it clear to which type they belong?

2. What indications are there in the text towards the interpretation of unclear implicit speech acts?

3. What aids are available, beyond the text, for the interpretation of unclear implicit speech acts?

4. What unclear implicit speech acts may be suitable for maximal argumentative interpretation?

5. Which literally interpreted speech acts contradict the general principles of communication, and are suitable for interpretation as indirect speech acts?

6. Which literally interpreted speech acts contradict the general principles of communication, and are suitable for supplementing?

\section{Analysis of argumentation structure}

An argumentation may be complex. Feiffer illuştrates in a cartoon strip a fairly complex argumentation. A woman says:

1. I have five different personalities.

2. I act childishly toward my mother.

3. I act maternally toward my father.

4. I dominate my husband.

5. I'm a sister to my daughter.

6. I flirt with my son.

7. Yet none of these is the real me.

8. Because the real me would dominate my mother.

9. I would flirt with my father.

10. I would be a sister to my husband.

11. I would act childishly toward my son.

12. And l'd make sure $I$ had as little as possible to do with my daughter.

13. Because she's like me.

In order to carry out an adequate analysis of more complex argumentative discourse, a distinction should be made between simple, multiple, coordinate, and subordinate argumentation. We speak of a simple argumentation if it is totally explicit (often not the case in practice), and consists of only two statements justifying or refuting a proposition, 
which together with the defended viewpoint form one complete argumentation:

a. Television encourages sociability (positive viewpoint with regard to proposition) because

1. Since we've had a television we no longer play cards and

2. Playing cards is unsociable (unexpressed premise).

b. Television does not encourage sociability (negative viewpoint regarding proposition) beause

1. Since we've had a television we no longer play cards and

2. Playing cards is sociable (unexpressed premise).

An argumentative discourse which contains this type of argumentation shows the basic structure of argumentation. More complex discourses always consist of a combination of argumentations with this basic struc- ture, and can be analysed as such.

Multiple argumentation consists of a number of simple argumentations which all relate to the same viewpoint and each of which is presented as an independent and conclusive defence. The speaker or writer can decide to use multiple argumentation if he senses his viewpoint is being confronted with various types of doubt from, for example, different antagonists. The following discourse illustrates a multiple argumentation:

I am of the opinion that postal delivery in the Netherlands does not proceed faultlessly because it can take longer than one day for a letter to reach its destination. Letters are sometimes delivered to the wrong address. Not to mention the fact that the time of delivery varies.

The argumentation structure of this discourse can be described as follows:

Postal delivery in the Netherlands does not proceed faultlessly.

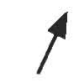

(1)

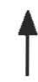

(2)

Letters are sometimes delivered Letters are sometimes delivered more than one day later.

to the wrong address.

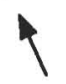

(3)

Delivery times vary.
Coordinate argumentation consists of a number of simple argumentations which (as in multiple argumentation) refer to the same viewpoint, but which only jointly are presented as a conclusive defence. While multiple argumentation can be regarded as a disjunction of simple argumentations, coordinate argumentaton should be regarded as a conjunction of simple argumentations. It is sometimes merely a question of interpretation whether one refers to a series of simple argumentations relating to the same viewpoint as multiple or coordinate. In order to give the speaker or writer optimal credit, in doubtful cases one should opt for a strategy of maximal argumentative analysis, which means that the argumentation should be regarded as multiple. Here follows a clear-cut case of coordinate argumentation:

\begin{abstract}
Meese is a true civil servant. He is bourgeois through and through. He prefers laziness to fatigue. And what's more, he finds rules more important than people.
\end{abstract}

This illustrates a coordinate argumentation because no one is supposed to believe that only civil servants prefer laziness to fatigue. It is the combination of the stated characteristics which label someone as a true civil servant. The coordinate argumentation structure of the discourse can be described as follows: 


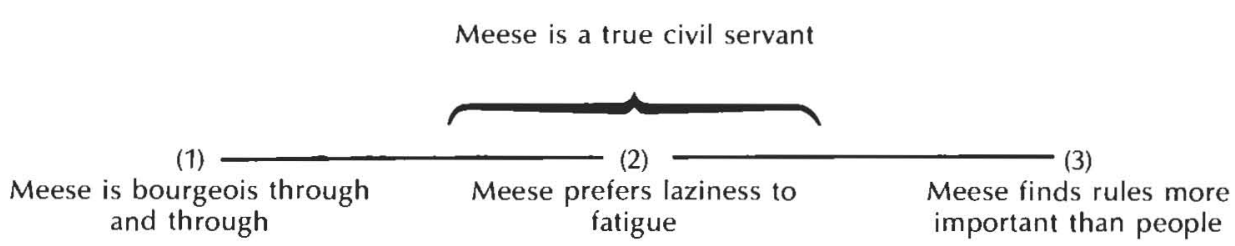

Subordinate argumentation consists of a series of simple argumentations which (as in coordinate argumentation) only together are presented as a conclusive defence of the viewpoint which initiated the argumentation, but which do not all directly refer to this viewpoint. Subordinate argumentation is argumentation which supports argumentation. This form of argumentation arises when an argumentation itself is doubted or assumed to be doubted. The following discourse illustrates subordinate argumentation:

John cannot possibly have been home because, since his mother-in-law was there, he's gone to play golf.

The subordinate argumentation structure of the discourse can be described thus:
John cannot possibly have been home

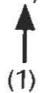

John has gone to play golf

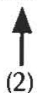

John's mother-in-law was there

Of course, a variety of other combinations of multiple, coordinate, and subordinate argumentations can occur, as the following discourse shows:

Bill is extremely spoiled. His wife is at his beck and call all day long. Not to mention the fact that Bill was an only child, and such children are always spoiled because the parents feel guilty at not having provided a playmate and so try to compensate by giving in to the little tyrant.

The argumentation structure is as follows:
(1)

Bill's wife is at his beck and call all day
Bill is terribly spoiled

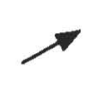

(2)

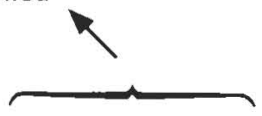

(3)

Bill was an only child - Only children are always spoiled

(4)

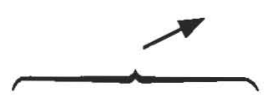

(5)

The parents feel guilty__ The parents try to compensate

A few questions can be formulated here towards analysing the discourse:

1. Which simple argumentations together form a multiple argumentation?

2. Which simple argumentations together form a coordinate argumentation?
3. Which simple arguments can be a multiple argumentation as well as coordinate argumentations, and should therefore be interpreted according to the strategy of maximal argumentative analysis as multiple? 
4. Which simple argumentations together form a subordinate argumentation?

\section{Argumentation analysis in school}

In the previous section we gave a rough outline of the first steps in a method of argumentation analysis. Even if this outline were to be expanded upon to form a more or less complete course of discourse analysis, and were to be supplemented with sections on fallacies and the evaluation of argumentation, this would still not render it immediately suitable for instruction on argumentation analysis in school. It is clear that a number of other conditions need to be fulfilled.

Firstly, space for argumentation analysis should be created within the teaching timetable. This can only be done if teachers recognize its importance. They will then have to present a convincing case for an improvement of the curriculum, which would involve attention being given to the way in which viewpoints are defended and difference of opinion are dealt with in everyday life.

Secondly, and this aspect should perhaps precede the first, in order to be able to teach the subject, teachers should be sufficiently au fait with developments concerning argumentation theory and analysis. In the Netherlands, development within the field has only recently become of interest to secondary schools; therefore too little attention has been given to it in teacher training programs. Some form of ducation permanente for teachers would be extremely worthwhile.

But the most important factor preventing the immediate implementation of argumentation analysis in schools is the lack of vital teaching methods. An elaborately worked-out theory of argumentation is simply not enough. An effective syllabus needs to be developed, with a suitable selection of examples and exercises. Moreover, this material should be presented using an adequate didactic method. This should make it clear in which manner and in what order the various sections can best be presented to the students, as well as the most suitable form of instruction and tasks to be assigned.

\section{An example of an analysis assignment}

A course in argumentation analysis should be structured in such a way that the students work step by step towards a final objective. This also applies to the fundamental section relating to the analysis of argumentative discourse. The final objective here is that the student should be able to draw up an analytical overview of an argumentative discourse. He should be able to identify the disputed points which need to be established; he should be able to interpret the discourse as part of a discussion which has the purpose of resolving the dispute; and he should be able to analyse the argumentation structure.

In order to demonstrate to where instruction in the analysis of discourse would lead, it is assumed here that the various stages of the learning process have been completed, and that the student should now be able to draw up an analytic overview of a discussion. This overview could, for example, be carried out on the following letter to the editor, which was published by a Dutch newsletter:

\section{Porno is not censorship}

How can porno be censorship? Women who claim this must be mad. I'd like to see them substantiate their claim. If the normal rules of logic mean anything to them, I can explain that porno has nothing to do with censorship. Porno does not prohibit anyone anything, nor is there a question of condescension, because nothing is thrust on anyone. It seems quite clear to me. Which is why I believe I am right.

A possible assignment regarding this text might be;

1. Indicate the points of dispute in the 
discourse which need resolving, and indicate what positions are adopted by those involved.

2. Indicate how far the discussion stages, which are theoreticaly covered in an argumentative discussion, are present in the discourse.

3. Give a description of the argumentation structure.

The assignment could be carried out in the following way:

1. The proposition initiating the dispute is: "Porno is censorship". According to the letter, some women adopt a positive viewpoint towards this proposition. The author expresses initially her doubt regarding the plausibility of this viewpoint, and as is illustrated in the statement heading her letter, she adopts a negative viewpoint towards the same proposition. This results in two protagonists: the women who support the viewpoint that porno is censorship, and the author, who disputes this. She and the women involved are presented in the letter as antagonists of each other's viewpoints. This instance is a mixed single dispute.

2 . The confrontation stage is represented in the women's viewpoint that porno is censorship, with the author doubting this viewpoint. She also expresses her own viewpoint that porno is not censorship. The opening stage is represented by the author challenging the women to defend their viewpoint, at the same time anticipating being challenged herself by the women or the reader. She also attempts to establish discussion rules by stating that the normal rules of logic will apply. On this basis, she takes up the assumed challenge. The argumentation stage is represented by the author, as protagonist of the viewpoint that porno is not censorship, presenting the coordinate argumentation that in porno, no one is prohibited anything, and that neither is there a question of condescension.

The last part of the argumentation

presented by the writer in this maximal argumentative interpretation is, in turn, supported by the argument that nothing is thrust upon anyone, which then results in a subordinate argumentation. The writer infers that, seen even from the point of view of the antagonist, her own argument is plausible. The closing stage is represented by the writer maintaining her viewpoint, and consequently claiming that the disputed point, that porno is not censorship, has been resolved in her own favour, due to her adequate defence of the viewpoint.

3. certain women: the author:

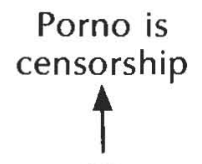

(1)

There is no question of anything being prohibited

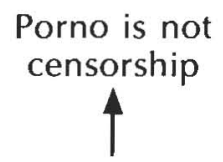

(2)

There is no question of condescension<smiles>[CH][CH]</smiles>

(3)

Nothing is thrust on anyone

\section{Notes regarding presentation}

The way in which the assignment in the previous section can best be presented naturally depends, among other things, on the nature and level of the group of students. It may be preferable with school children to allow a different child to complete each stage, while adults may prefer one member of the group to carry out the total analysis, followed by a general discussion on the results.

With regard to the contents of the presentation, however, further comments are in order. It is necessary to continually make sure that the individuals who carry out the assignments are aware of the meaning and purpose of the various sections of the exercise and, consequently, are aware of the criteria necessary in the evaluation of their 
answers. It should be taken into account that an analytic overview of an argumentative discourse is a special kind of summary. It is an oral or written report in which the text illustrating the discourse is not just summarized, but a systematic indication is given of which elements in the text are of direct importance for resolving the dispute.

\section{Bibliographic Note}

The following titles serve as works of reference for the material presented here in concise form, as well as sources of further information on the various subjects. Because we tried to explain our own viewpoints here, we refer solely to our own works, but in these books we refer to publications by other authors which are significant.

Eemeren, F.H. van, R. Grootendorst, and T. Kruiger. Handbook of Argumentation Theory, Dordrecht, Holland/Providence, USA 1987: Foris. PDA 7.

This book illustrates the different ways in which leading argumentation theorists deal with argumentation. Following an outline of general background information on argumentation theory (classical logic, dialectics, rhetoric, the principles of fallacies, modern logic), a description is given of the most significant modern contributions (Naess, Crawshay-Williams, formal dialectics). Toulmin's well-known model of analysis and the influential New Rhetoric of Perelman and Olbrechts-Tyteca are dealt with in a separate chapter. The book contains an extensive alphabetical and systematic bibliography.

Eemeren, F.H. van, and R. Grootendorst. Speech Acts in Argumentative Discussions. A theoretical model for the analysis of discussions directed towards solving conflicts of opinion. Dordrecht, Holland/ Providence, USA 1984: Foris. PDA 1.

The general aim of this study is to establish theoretically motivated guidelines for the analysis of argumen- tative discussions, and to formulate rules for a code of conduct for reasonable discussants.

Eemeren, F. H. van, and R. Grootendorst. Argumentation, Communication, and Fallacies. To be published.

Starting from the theoretical background sketched in Speech Acts in Argumentative Discussions (see above), van Eemeren and Grootendorst systematically point out that argumentation discourse can be analyzed as part of a critical discussion between two parties who are trying to resolve a dispute and that fallacies can be analyzed as violations of a code of conduct aimed at furthering such resolution. For this purpose Searlean insights concerning speech and Gricean insights concerning co-operative verbal interactions are integrated into a comprehensive approach to communication. This approach is used to deal with the problems encountered when interpreting argumentation discourse and when analyzing complex argumentation. Having supplied the instruments for examining the stages in which a critical discussion develops, for each stage the rules are given of the code of conduct, fallacies are then analyzed as specific violations of this code. An endeavour has been made to lay new and sound theoretical foundations for the analysis of argumentation and for systematically detecting and characterizing fallacies.

It is explained what sort of speech act is performed when argumentation is put forward, which conditions may be regarded as having been fulfilled when that speech act is performed, and what the relation is between the peformance of that speech act and the perlocutionary effect that the listener or reader does or does not accept as a standpoint. Furthermore, guidelines are formulated for explicitizing unexpressed premises.

Frans H. van Eemeren and Rob Grootendorst, Instituut voor Neerlandistiek, Universiteit van Amsterdam, Spuistraat 134, 1012 VB Amsterdam, The Netherlands. 